\title{
Modern Financial Markets and the Complexity of Financial Innovation
}

\author{
Oxana L. Wieland \\ Department of Business, University of Minnesota Crookston, United States
}

Copyright (C) 2015 by authors, all rights reserved. Authors agree that this article remains permanently open access under the terms of the Creative Commons Attribution License 4.0 International License

\begin{abstract}
Social investing will be examined as an example of modern institutional innovations with respect to the complexity of financial markets. Social impact bonds will be used as a case study of a particular innovative financial instrument in order to understand the complexity and resulting challenges of these potential market dynamics. The author argues that post-crisis regulatory regime governing US and European markets require substantial work to fully address the challenges derived from financial innovations. In particular, existing regulation, technologies, information asymmetry, agency cost, and innovation pace need to be considered in order to understand the factors which will determine likely outcomes of social impact bonds. Social Investing and the embryonic stage of current development reflect certain 'unknown areas'. This paper addresses the needs of the post-embryonic stage of the theoretical framework of financial market innovations.
\end{abstract}

Keywords Social Impact Bonds, Financial Markets, Financial Innovation

\section{Introduction}

Financial market complexity has led to innovations such as social impact bonds ( $\mathrm{SIB}(\mathrm{s})$ ) which themselves add to the complexity of financial markets. To understand the relationships between these innovative instruments, complexity itself must be examined in the context of today's financial markets. In this paper, the author examines financial market complexity, innovation in the form of the SIB and its short history, and suggests that these phenomena will require methods of study which are as new and innovative as the instruments and the environment they operate in.

\section{Materials and Methods}

Materials used in this research include recent social investing publications as well as sources found on the web sites of institutions engaged in relevant financial activities. Review and analysis of this information is reflected in this paper.

\section{Discussion}

Modern finance theory is based on three primary assumptions: 1) Perfect information 2) the absence of transaction costs 3) rational market participants. These assumptions are rarely if ever in seen in the real world of financial transactions in the market. Awrey argues that it is exactly these assumptions which created 'blind spots' that substantially contributed to the global financial crises (GFC) [1].

"These theories share a common and highly stylized view of financial markets - one characterized by, inter alia, perfect information, the absence of transaction costs, and rational market participants. Yet in reality financial markets -and market participants - rarely (if ever) strictly conform to these assumptions. Information is costly and unevenly distributed, transaction costs are pervasive and often determinative, and market participants frequently exhibit cognitive biases and bounded rationality." (1)(2012:1)

"Prevailing dogma prior to the GFC viewed the seemingly insatiable demand for many species of OTC derivatives as a rational response to market imperfections. Supply, in turn, was a rational response to this demand. That supply met demand within the marketplace was then generally interpreted as being dispositive of these instruments' private and social utility. This viewpoint was firmly rooted in the autonomous rational actor framework underpinning $M P T$, the M\&M capital structure irrelevancy principle, CAPM, and the EMH." (2012, Pg.4)

The basic tenants of modern finance stem from modern portfolio theory (MPT), Modigliani and Miller (M\\&M) capital structure irrelevancy principle, the capital asset pricing model (CAPM), and the efficient market hypothesis (EMH). 
Modern portfolio theory is a mathematical formulation aimed at balancing the risk and return of a portfolio of investments such that the risk of the overall portfolio is less than the risk of any given asset in the portfolio. The diversification of the portfolio addresses systematic risk and the assumption is that unsystematic risk is negligible.[2](Pg. 434) . Risk in a well balanced portfolio can be determined by measuring the overall risk against the expected and unexpected returns, the standard deviation of which determines the total risk. The assumption is made that the investors are rational and the market is efficient. The sum of systematic risk (risk across all assets in the market) and unsystematic risk (risk unique to given asset) comprises the overall risk of a given asset1.[2](Pg. 445) Establishing the security market line(SML) is part and parcel of determining the risk of given assets within the portfolio. There is an implied assumption that data is available with which the formula can be populated.

The complexity factors of opacity and fragmentation evident in securitizations (ex. asset backed securities) renders the implied assumption of information availability questionable as the amount of data and its availability is prohibitively costly to acquire and analyze. Because the true underlying value of any given asset can be masked by opacity, the $M \backslash \& M$ theory becomes difficult to apply as the total value of assets itself becomes hard to determine.

The complexity of financial innovations renders the effort to collect, analyze and act on the mountainous volume of data nearly impossible, not to mention costly resulting in opacity. Therefor a key factor in understanding complexity is how tolerant actors are of complexity and what that complexity consists of. (Data driven decisions?)

\subsection{Complexity}

Complexity is driven by innovation and innovation by three primary motivators: 1 ) the demand to address market inefficiencies 2) the drive to gain market share 3) the interest intermediaries in sales of products. To understand the relationship between the complexity and innovation, each must be examined.

According to Awrey[2], complexity is composed of two primary components: 1) The cost of information 2) the cognitive ability of participant to process the information then gleaned.[2] (Pg 11) Complexity can be broken down into six component parts: technology, opacity, interconnectedness, fragmentation, regulations and reflexivity.[2] (Pg 14)

1. Technology: Serves to both reduce and increase the cost of information by increasing the amount of data that can be processed, as well as increasing the amount of data to be processed.

2. Opacity: Securitization in the form of mortgage backed securities, for example, make determining the actual value of market instruments, and who is responsible for the components of those instruments difficult and costly. Additionally, the amount of information that describes these instruments is prohibitive to understanding them in a way which would allow a reasonable evaluation of their value and risk.

3. Interconnectedness: The number of institutions/participants rolled into an instrument makes determining the combined risk of the instrument difficult. Asset backed securities may involve many underlying risk components of varied risk value spread across numerous institutions serving different components of the global market.

4. Fragmentation: Contributes to opacity in that it renders difficult the effort to understand the interests of the many parties/counterparties represented by a single transaction.

5. Regulation: Both structural and substantive complexity of rules. Numerous regulatory bodies may have mandated interest in a given instrument, thus making it difficult for both the participants and the regulators to determine, much less coordinate the rules that are supposed to protect market participants.

6. Reflexivity: Participants react to observations of the dynamics of the market, thus changing the market being observed.

\subsection{Innovation}

Innovation may be thought of as a primary contributor to complexity. In simple terms, innovation has traditionally been defined as change in the interest of improvement. However, improvement is subjective in that it scales based on the observers point of view. Innovation then breaks into two components: 1) change, real or perceived and 2) the effect on the financial landscape. Additionally, the nature and pace of innovation also are contributors to complexity [1]. (Pg. 5)

The conventional view of innovation is that innovation takes place in response to perceived inefficiencies in the market as determined by consumers of financial instruments (demand side innovation). The less common view is that innovation is derived from competition between financial institutions attempting to gain market share (supply side innovation). Both of these views leave out an important component: That of the intermediary between the instrument issuers and the investors [1] (Pg. 35). The intermediary has often been the originator of innovation in order to increase the number of offerings it may present to investors in order to increase sales. Thus, the two primary theories of innovation drivers ignore a significant source of innovation.

The intermediary does not have a significant interest in ensuring the value of any given financial product to either the investor or the issuer. The intermediary is generally paid up front based on a sales commission and/or a service fee. As a result, innovation generated by an intermediary is not addressed by either the supply side or the demand side theories of innovation drivers and in fact is a likely contributor to agency cost.

\subsection{Social Impact Bonds (SIBs)}




\subsubsection{SIB - Introduction}

Social Impact Bonds are a relatively new concept in the world of finance. Also known as Pay for Success Bonds (US) or Social Benefit Bonds (Australia), the basic concept is to relieve or mitigate what are traditionally considered to be social issues using complex investment tools. Issues that would usually be taken on by the government or philanthropic organizations are instead viewed and treated as investment opportunities which are intended to show returns for investors as well as serving the social good[3].

The Social Impact Bond (SIB) is a complex debt instrument which is intended to address perceived inefficiencies and poor performance of long running and costly social programs by providing the needed start-up financing to establish high performing projects targeting social issues such as recidivism, providing running measurements of success, as well as tax payer risk reduction. The sustainability of social outcomes is one of the main target characteristics of successful SIBs, where a key measurement of the projects goal is not only to address symptoms of issues, but also show long term mitigation or reduction of the cause(s) of the issue addressed, thus proving to be preventative measures[4].

There are several 'definitions' of SIBs, though they all agree on basic goal of addressing social issues. The differences lie primarily in who may invest in the bonds. By some definitions, the public sector is excluded from investment whereas others allow or even encourage public sector investment.

The SIB is considered to be a part of the 'fourth sector' of the economy. Traditional sectors are describes as nonprofit, government, and business, the SIB could be thought of as a meta-sector encompassing and attempting to coordinate the efforts to the traditional sectors in addressing social issues.

\subsubsection{History}

The term "Social Impact Bond" was reportedly coined by Geoff Muligan, Chief Executive of the Young Foundation. The first SIB was announced in March of 2010 and subsequently launched in September of 2010 in the United Kingdom with the goal of reducing recidivism in Petersborough[5]. It was the result of effort by UK the Prime Minister's Council on Social Action. Subsequent interest in the concept was shown in the United States, and Australia with further interest shown by Israel, Canada, France, Germany, Korea, Australia, India and Ireland6.

In 2007, the organization called Social Finance [7] was established to, among other things, offer services in helping to establish SIBs. In 2011, Social Finance US [8] was established to offer many of the same services, but tailored to the US markets. Additionally, in February, 2011, Barack Obama proposed $\$ \$ 100$ million be targeted to SIB pilots.

In 2013, the United States established a National Advisory Board "comprised of 27 thought leaders from various areas of expertise including private investors, entrepreneurs, foundations, academics, impact-oriented organizations, non-profits, and intermediaries"(pg 3, Private Capital, Public
Good - US National Advisory Board On Impact Investing, June 2014). This body was created to support the growth impact investing by highlighting key areas of focus in the policy arena [1]

There are currently twenty agreed SIBs in the United Kingdom9 and fourteen throughout the rest of the world. The stated goals of the proposed and agreed upon SIBs include homelessness, unemployment, youth outcomes, and early childhood education [Table 1] [8]

Table 1. Non-UK SIBs agreed upon

\begin{tabular}{|c|c|}
\hline Local & Program/Target \\
\hline $\begin{array}{c}\text { Ricers Island-New York } \\
\text { USA }\end{array}$ & Young ex-offenders \\
\hline New South Wales Australia & Families with children in care \\
\hline New South Wales Australia & Families with children in care \\
\hline Granite School District Utah USA & Early childhood education \\
\hline Rotterdam The Netherlands & NEETS aged 17-27 \\
\hline $\begin{array}{c}\text { New York State Dept. Of Labor } \\
\text { USA }\end{array}$ & Employment for ex-offenders \\
\hline Massachusetts USA & High-risk young men \\
\hline Brussels Belgium & Employment for young migrants \\
\hline Saskatchewan Canada & Single Mothers \\
\hline Augsburg Germany & NEETS \\
\hline Chicago USA & Early childhood education \\
\hline Cuyahoga County USA & Children of homeless families \\
\hline Massachusetts USA & Homeless people \\
\hline Portugal & Education \\
\hline
\end{tabular}

\subsubsection{Purpose and Goals}

The Social Impact Bond is designed to address both the systemic and financial shortcomings of traditional social programs by focusing the efforts of key players on coordinated strategies, sometimes referred to as 'interventions', that address well defined social issues with clearly stated outcomes for a targeted population. Important terms in discussing SIBs are outcome, intervention and population.

An intervention is an activity or set of activities that addresses an issue which has been clearly defined.

An outcome is the desired result of the intervention which has clear measurements by which to determine success.

A population is a group of people targeted by an intervention for which the outcome is determined to be beneficial.

Long running government social programs are perceived to be costly and ineffective in that the problems being addressed continue to grow, or do not shrink in magnitude over time while continuing to drain public funds. Programs implemented by philanthropic organizations are often seen to overlap without coordination, in some cases duplicating efforts with differing methodologies aimed at the same target issue. Additionally, the philanthropic efforts are often in competition for the the limited funding available from both governments grants as well as charitable offerings. This 
competition injects inconsistency in the availability of the services offered, thus reducing the effectiveness and sustainability of similar but independent efforts.

The SIB is intended to provide funding and an organizational framework around that funding source which incorporates the key players in a more effective and targeted coordinated effort which is itself sustainable. Once established, the SIB provides the often hard to attain start-up funding as well as long term funding which enables the intervention to establish itself and continue with the confidence that financing is available. Additionally, the SIB attempts to structure efforts across boundaries of individual service providers so that the target population is provided with 'bundled services' from one organization instead of many services from many organizations. That bundling of services is intended to address the cost efficiency, long term effectiveness and sustainability of the outcome. By providing a potential return on investment, the SIB may draw the interest of parties which normally would not release funds for socially impact based activities. Less risk-averse institutions may be willing to free up funds when there is a potential for a return. One of the goals of the SIB is thus to draw in funds which would not be made available in other situations.

Government programs are variably constrained and thus tend to provide inconsistent performance over time. Additionally, new approaches to social problems are a hard sell due to public reaction if a new program fails or is perceived to fail.[10]

It has been argued by some that philanthropic endeavors are not a substitute for government programs. SIBs provide an example which supports the argument that philanthropic endeavors influence government interventions by providing a guide for government increased investment in targeted areas [18].

The intervention is monitored by an independent entity based on performance measures stated in the accepted SIB proposal. If at any time the measurements indicate a lack of performance relative to the intended outcome, the investors lose their investment, no payment is made by the government, and the program ends. If, on the other hand, the performance measures indicate that the goal has been attained, the government repays the investors with interest out of funds saved by the government as a result of the issue being reduced or mitigated.

Social impact bonds may be applied to either remedial or preventative services. The government may often be the initiator of the SIB, however service providers or intermediaries may also propose an SIB to the government after doing preliminary design work.

\subsubsection{Structure}

A social impact bond is not technically a bond in the traditional sense [4]. Investors in SIBs are at risk to lose $100 \backslash \%$ of their investment if the outcome is not achieved. Additionally, SIBs are not an instrument which can be bought or sold [11]. The SIB is instead a collection of contractual agreements made between key players which describe the responsibilities, parameters and benefits of each of the players.

The key components (players) of a SIB are the; Government, intermediary, investors, service providers, and the independent assessor or evaluator.

The government: is generally the initiator of the SIB contract and set the outcome, time frame and population. In the US, state, county, and local governments have been the primary government participants.

The intermediary: provides overall management and may be seen as a project management provider. The intermediary may be a for-profit or not-for-profit organization.

The investors: provide capital to pay for the intervention. These are the players that take on most of the financial risk of the SIB.

The service providers: provide the expertise in the area of the social issue being addressed by the SIB. The service providers usually receive grants which are funded by the investors to fund the service they provide.

The independent assessor: determines, documents and reports on the work in progress and eventually the outcome of the SIB based on agreed upon measurements by the other key players.

SIBs need not always follow the same model as was developed by the UK in the Peterborough SIB where the intermediary (Social Finance in this case) is at the center of the transaction fulfilling multiple roles. Government may instead contract directly with service providers. In Minnesota (US), the legislature will issue new debt to finance investments in preventative social programs.

\subsubsection{SIBs in the United States}

The United States Federal Government entered into the social impact arena beginning in 2012 with the establishment of the US National Advisory Board On Impact Investing (NAB)1. The NAB issued a final report indicating that the growth of SIB investments in the US in 2014 over the previous year had been $20\lfloor \%$. The report also states that this is believed to be marginal as compared to the potential.

New York City was the first to initiate an SIB in the US intended to address recidivism at the Ricers Island Penitentiary and is scheduled to complete in August of 2015.

Recent announcements by representatives indicate that there the concept of the SIB is gaining traction politically. The states of Colorado and South Carolina have initiated the beginning phases of SIB design as of June of 2013[12]. Additionally, the Harvard Kennedy School "Social Impact Bond Technical Assistance Lab" has received applications for and granted assistance to Arkansas, District of Columbia, Nevada, Pennsylvania and San Francisco in the early months of 2015. The grant recipients were selected from a group of applicants.[13] Funding is provided by Goldman Sachs with Bloomberg Philanthropies providing guarantees to investors of approximately three quarters of the total funding. 


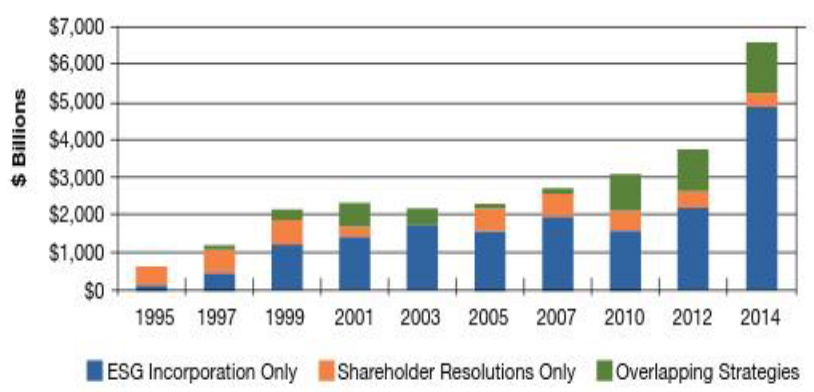

SOURCE: US SIF Foundation.

Figure 2. Sustainable and Responsible Investing in the United States 1995-2014

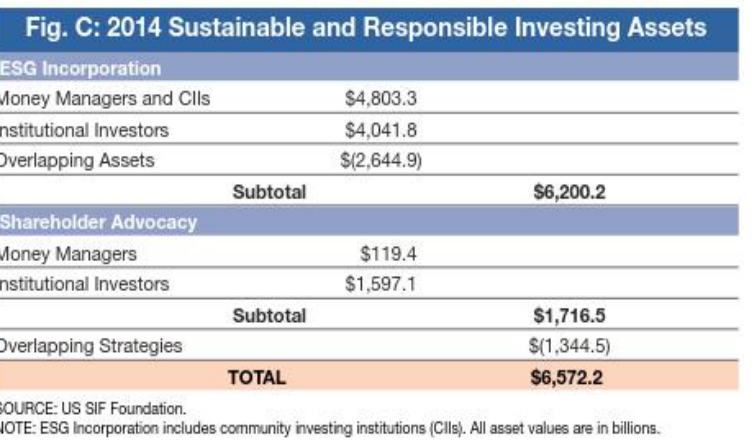

Figure 3. 2014 Sustainable and Responsible Investing Assets

\subsubsection{Observations}

1. Structural Conflicts - Several of the early Pay for Success Bonds developed in the United States are targeting recidivism. One particular challenge that will likely present itself United States lies in the fact the many of the prisons are owned and operated by publicly traded firms which answer to shareholders and therefore must show both profitability and growth to remain viable. This would at least on the surface appear to put the government in a position of conflicted interests. While contracting with these firms to take care of the prison population, the government (whether state or federal) may also be investing in programs to reduce prison populations. Regardless of whether or not the government has actually invested public funds in the relevant SIBs, as a primary stakeholder, the government will in effect be attempting to put out of business those that it has contracted with. How such challenges might be addressed, or if they will appear remains to be seen. Never the less, it is conceivable that this conflict my present itself and implies some forethought by the potential investors in SIBs that fit this profile

2. Current Economic Environment - The recession of 2008 and the reaction to it by many governments has and continues to put government social programs in danger of reduced funding or, in some cases, a termination of the programs entirely. Austerity measures in the US, the UK and in the European Union have had impacts on such programs. It therefor natural that governments look to alternate measures to address the social issues without risking current scarce revenues or taking on the political risk of funding replacement programs which commit future revenues that they have to answer for. SIBs are attractive in that they don't require that the government provide up-front funding, and yet plays a role in providing needed services while reducing the risk of failed programs. "Why are so many governments interested in SIBs? SIBs offer an answer to a question all policy makers are facing in these difficult fiscal times: How do we keep innovating and investing in promising new solutions when we can't even afford to pay for everything we are currently doing? SIBs also align well with the spread of data-driven leadership practices focused on improving government performance and with government efforts to collaborate with nonprofit and for-profit partners in solving community-based problems."[15]

3. Receptiveness - In spite of the proponents and quick growth of the concept of SIBs, there are elements of the public and private sectors which are not receptive to this new innovation. In a 2011 paper[16] published by the Young Foundation, Mulgan, Reeder, Aylott and Bosher state: "That said, SIBs are unlikely to be able to meet all of the expectations being placed on them, and they face important challenges, of which three stand out: - The relative weakness of the evidence base (and resulting difficulties facing any investors or banks wanting to judge the risk of a particular set of interventions, and the bodies being funded to carry them out); - Overlaps with existing public programs. In a world with no public spending, SIBs would be relatively straightforward. However, they depend on demonstrating a causal link between additional spending and outcomes achieved. This is hard for target groups already in receipt of public support, such as young people under 18. To solve the problem, either contracts or measurement systems have to become complex -and require other public agencies not to cut or change existing programs -or some form of partnership agreement is needed which ties in with other public provider; ${ }^{-1}$ ssues of scale and transaction cost. Most PFIs under about $£ 25 m$ turned out to be uneconomic due to the high transaction costs. There may be a similar lower limit for SIBS, which is challenging given that any pilots are likely to be on a significantly smaller scale. In addition SIBS face the challenge that also faces all new financing tools around public services, namely that governments always have a significantly lower cost of capital than other bodies."

\subsection{Socially Responsible Investing As a Form of Complexity}

Social impact investing (SSI), while not new [24][25], is an active form of financial innovation and thus, a contributor 
to modern financial complexity[21]. Early forms of SSI were from a motivational point of view rather simple and came in the form of boycotts [22] driven by political motivations of investors. Subsequent developments of motivations including those listed by the UN Millennial Development Goals [23] added complexity in response to a interest a wider set of issues, social and otherwise.

There are several definitions of impact investing however they share in common the concept of "the achievement of positive societal, environmental, or sustainability impact by capital investments" - while generating a financial return for the investors.[16](Pg. 161, Olaf Weber and Yayun Duan, Social Finance and Banking)

\subsubsection{The Complexity of the SIB}

The Social impact bond (SIB) is one example of a new, innovative and complex financial instrument which means to address social issues which have traditionally been addressed by government programs and/or philanthropic organizations, generally exclusive of each other, whether at the local, county, state or federal levels. SIBs blend these two institutions and the additional component of market investors in a complex contractual relationship intended to address the perceived challenges of traditional program approaches. In particular, the startup costs of new programs are often prohibitive. In many cases, only a government has access to the funds required to start and maintain a new social benefit program. Government programs however are often long running and address the symptoms of a problem without mitigating the core of the problem as evidenced by steady or increasing numbers of people served by some government programs. In an environment of shrinking budgets, it is politically risky to argue for the continuance of existing programs, not to mention fund new ones. The perceived benefit of SIBs is that the government does not have to fund as much, or in some cases any, of the upfront costs of a new program. More importantly, the government in some cases does not have to pay out at all if the program does not achieve the agreed upon outcome of the program. In that case the investors have assumed all the risk and lose their investment. In cases where the outcome is achieved, the government pays out of the calculated savings the program generated by reducing the demand for government services.

SIBs however are not a simple instrument as is there partial namesake, the municipal bond or Treasury note. In fact, SIBs are not really bonds at all, but instead a complex set of negotiated contracts between numerous key players. A key difference is that an SIB cannot be traded, unlike traditional bonds.

Partially because of the relative newness of SIBs, several of the causes of 'unknown areas' particularly apply to the challenge of understanding them. There is very little empirical data indicating the success or performance of SIBs. There are as of yet no regulations specific to SIBs. Measurement of success or failure is based on contractual agreements, and therefor can be somewhat subjective. It is unclear what the cost of agency really is. The number of unique SIBs has grown rapidly since their conceptual introduction in 2010 and the first implementation in 2012, and now numbers over twenty suggesting, if not rapid innovation then certainly rapid deployment of the new innovation. As a result it will likely be challenging for regulators and direct participants to use traditional theory to assess risk or valuation of any given SIB.

The existence of the SIB as a concept implies that there is capital being made available which does not fall under the traditional theory of modern finance. An SIB is a high risk investment with at best a moderate long term ROI. There many investments for which the ROI would far exceed that of an SIB. Clearly there is something other than 'market rationality' involved in taking on an SIB. Two contrasting categories of social impact investor are the 'values-driven investor vs. the profit-driven investor. Each uses a different 'screening' method for determining what to invest in. It could be argued that the value-driven investor simply has a longer term expectation of ROI. [20]

The basic tenants of modern finance stem from modern portfolio theory MPT, Modigliani and Miller $(\mathrm{M} \backslash \& \mathrm{M})$ capital structure irrelevancy principle, the capital asset pricing model (CAPM), and the efficient market hypothesis $(\mathrm{EMH})$. All of these are based on an assumption of the availability of perfect information, no transactional costs and rational market participants. As noted earlier, the latter of those three do not fit with those who are investing in SIBs. Additionally, there is a lack of information, or information asymmetry, due to the newness of SIBs. SIBs, because of their complex contractual composition, may also impose substantial agency cost. Consider also the fact that US and European monetary policy might be considered non-standard currently, with interest rates being held at all-time lows. The impact of these policies and their highly anticipated future moves toward 'normal' rates provides for a substantial uncertainty when looking at an innovative investment such as an SIB which will most certainly factor into the value of ROI on long term investments. The Fisher Effect must be almost factored out of the participants' equation, thus leaving open the question of the 'rationality' of the participants.

Examining SIBs within the context of the basic tenants further exposes not only the 'blind spots' or 'unknown areas' which are pointed out by Awrey [1](Pg. 1), but also that the entire area of such investment mechanism have no theoretical backing in traditional theory. The SIB is not quantified or qualified by the tools of traditional financial theory.

For example, it could be argued that Bond Interest Evaluation of SIBs is from the perspective of the investor is a non-impactor. The 'bond' yields only if the criteria of the SIB are met and then only pays back the amount saved by the government. Because SIBs are not traded, variable interest rate does not impact the payout. However, the value received by the government or philanthropy (or both) may be impacted by inflation. Because current interest rates do not reflect a healthy market economy and there is no empirical 
evidence of SIB performance, there is little chance of calculating the future value of the outcome of the SIB should it achieve its desired outcome.

That having been said, there are existing tools and models which have been applied to social impact investing in its other forms which can be applied to SIBs which can assist the investor. That having been said, there are existing tools and models which have been applied to social impact investing in its other forms which can be applied to SIBs which can assist the investor in determining the potential of a given investment in both financial as well as social impact terms. As an example: A credit scoring system based on a model comprised of two components has been suggested which uses both the conventional banking model combined with the United Nations Millennium Development Goals through a technique called the Analytic Hierarchy Process[17]. This model provides a way to delve through the complexity of both quantitative and subjective criteria for social investing the potential of a given investment in both financial as well as social impact terms. As an example: A credit scoring system based on a model comprised of two components has been suggested which uses both the conventional banking model combined with the United Nations Millennium Development Goals through a technique called the Analytic Hierarchy Process[17]. This model provides a way to delve through the complexity of both quantitative and subjective criteria for social investing.

\subsubsection{Norfund - A Broader Form of SSI}

Norfund is a public institution established as a Development Finance Institution (DFI) which was established by the Norwegian Parliament in 1997. The primary goal of Norfund is: ".to contribute to sustainable commercial businesses in developing countries."[26] Sustainable in Norfunds case includes issues of poverty, environment, equal rights for workers, and in particular women. Norfund may take partial ownership of companies or simply act as a lending institution targeting small and medium sized businesses in developing countries such as Uganda.[27]

While SIBs target social issues within the confines of a given country, Development Finance Institutions like Norfund work across national borders, attempting to address many of the same issues. Unlike SIBs, DFIs are usually publicly funded and address social issues by attempting to positively impact the underlying fundamental elements which provide opportunity for those in society.

There are some marked differences in the criteria for providing funding between an SIB and a DFI. One of note is the existence of policies on corruption and human rights (child labor for example) (Page 51)[28]. The author has not seen these issues addressed specifically in the criteria for SIBs. The scope of SII investing between the two is very different even though the intended outcomes are related. In some ways, there is evidence of standards and measurements such as IFC Performance Standards on Social and Environmental Sustainability(Page 34 [28])[29] being in place for SSI at the DFI level. This is an example which shows the maturity of DFI as an SSI endeavor as compared to the relatively recent emergence of SIBs. That maturity addresses complexity in ways which have yet to be developed in SIBs.

Norfund expresses complexity in the variety of models it has at its disposal with which to invest, from direct ownership to financing only, including mechanisms for impact at a small scale such as micro-finance. Once again this exemplifies complexity for investors as well as other key players such as regulators from the country of the SSI source and the target country. In spite of this, it is clear that there are well establish standards against which to determine compliance and measure success (Page 2[29]).

\section{Conclusions}

\subsection{A Developing Economic Phenomena}

Social Impact Bonds are a very new arrival in the world of finance. Because of this, there are as many questions about them as there are answers. With only one major SIB in progress and none which have reached the intended outcome, or for that matter, failed to do so, it is impossible to draw conclusions based on outcomes. However, the complexity of the instrument as well as its intended goals will bear watching closely as more SIBs are agreed upon, are implemented and reported on.

Clearly there is significant interest and effort being put forward by both public and private institutions at all levels to indicate that SIBs will be playing a role in social and financial arenas for some time. Early adopters have shown a propensity for being open with information regarding the progress as evidenced by their prolific dissemination of information on the web, at academic and business conferences. This should provide ample opportunity to examine the further development of the SIB as a financial instrument and the performance of individual SIB implementations. The fact that the concept is being taken seriously is made clear through public pronouncements by several US politicians as well as the support shown by political actors in the UK, Australia and other countries. Whether the growth of SIBs continues may well depend on global economic factors. The recent macroeconomic environment may well have played into the early attention SIBs have enjoyed thus far. As world economies stabilize, will the SIB still be seen as an attractive alternative to addressing social issues?

\subsection{An Opportunity for Academic Study}

Current theory does not address the social aspect of Social Impact Investing (SII). While social impact investing has shown that there are ROI advantages, the same cannot be said of SIBs. So what is the driving force behind the Social Impact Bond? Clearly current theory does not explain nor 
even address such phenomena. While it is simple enough to say that those potential participants who have achieved success and have the ability to direct resources to such endeavors do so for altruistic reasons, there is no fully developed body of theories to describe the social component of the social impact investment participants.

Thus, there is an urgent need for interdisciplinary research conducted which strives to both qualify and quantify the basic drivers and mechanisms which contribute to the development of SII. In particular, the fields of behavioral sciences such as behavioral economics, behavioral marketing, behavioral finance and others should be combined with the traditional fields of study in economics and finance to begin to understand the new and innovative instrument inclusive of the participants. These new financial course offerings need to he directed at the goal of creating the opportunity for not only their stated individual learning purpose, but to encourage the academic community to explore and develop theories which might explain the behavioral phenomena involved.

There is a large body of works which describe innovations in finance, and a budding field of work in the behavioral sciences regarding finance and economics. The author would argue that both fields would benefit from the continued advance of the behavioral sciences. For example, a major might be offered in behavioral economics in the context of economic policy or financial innovation and complexity with the focus on the actors within the institutions instead of the institutions themselves.

Additionally, there is a great opportunity for the behavioral sciences to examine the long term impacts and outcomes of international social impact investment exemplified by DFIs such as Norfund. Incorporation of the behavioral sciences in International Business and Interdenominational Finance curriculum could well provide a mechanism for better understanding of the complexities of such endeavors.

An indicator of moving from the embryonic stage of development would be if we were to see the implementation of new academic disciplines and educational programs such as courses in social investing, and corporate responsibility throughout the academic levels.

\subsection{Structural and Institutional Development}

Structural institutional support in the form of policy will also be needed in order to extract the maximum value of SIBs and to insure that the investment become available to the wider market. A study by BNY Mellon as reported in an on-line article clearly identifies and suggests solutions to some of the institutional challenges of social impact investing.[19] While altruistic efforts of large companies, philanthropies and the wealthy are the current source of the apparent popularity and success of creating SIBs and social impact investing in general, it is likely that a great deal more could be done and resources brought to bear if SIBs were offered on the open market in a more diverse product offering[19]. In the interest of that, Institutional support in the form of indexes as well as corporate performance indicators regarding the social impact investment activities should be established enabling those who wish to invest in SIBs to understand the choices available for their investment dollars. Information regarding existing and planned projects are an important source for investors to examine conformity to best practices. Further development of the mechanisms for trilateral (state, corporate, not-for-profit) and possible multilateral partnerships that are aimed at further development of social investing as a new financial form of solving urgent social, economic and environmental issues.

In order for innovative products such as SIBs to reach their full potential of expanding the realm of SII, there will also need to be policy[19] changes in the form of well-developed legislative framework that specify interested parties responsibilities and interaction schemes which encourage investment in them. Tax incentives for those who invest would be a common approach to addressing such a need.

DFIs such as Norfund offer an opportunity for modeling SIB development using standard established by the UN and participating partners involved in SSI at the DFI level. The maturity of these broadly scoped international SSI efforts may very well be adopted in some form for newer complex financial instruments such as SIBs.

\section{Appendix}

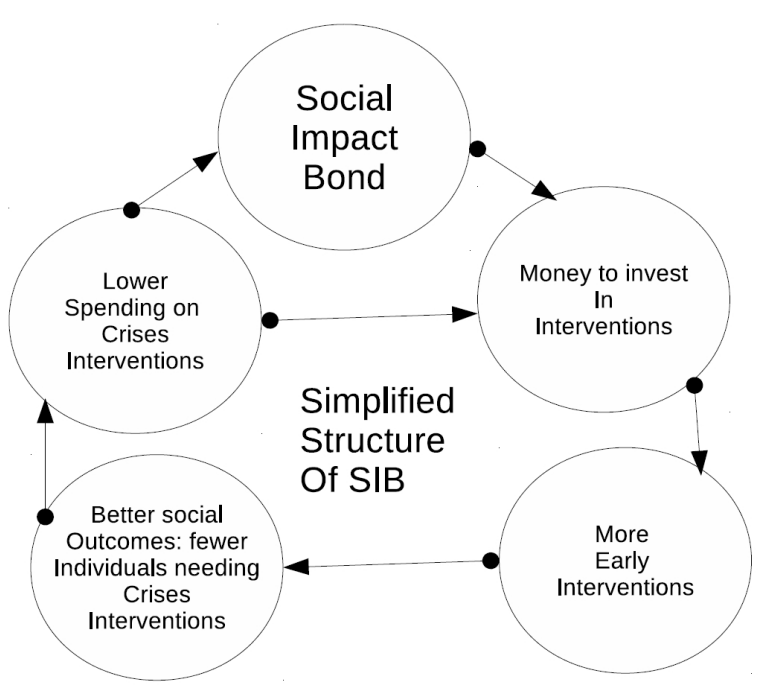

Figure 1. from Manage Styles to Import/Export.

\section{REFERENCES}

[1] Awrey, Dan, Complexity, Innovation and the Regulation of Modern Financial Markets (September 1, 2011).(2012) 2:2 Harvard Business Law Review 235; Oxford Legal Studies Research Paper No. 49/2011. Available at SSRN:http://ssrn.com/abstract=1916649or 
[2] Ross, Stephen A. Fundamentals of corporate finance / Stephen A. Ross, Randolph W. Westerfield, Bradford D. Jordan. 11th ed., Alternate ed. New York, NY: McGraw-Hill/Irwin, c2014.

[3] US National Advsory Board on Impact Investing, http://www.nabimpactinvesting.org/s/ $\wedge$ Private $\backslash$ Capital $\backslash \mathrm{Pu}$ blic \_Good-pamn.pdf.

[4] Anna R. Kimbrell, Seven Pillars Institute Moral Cents Vol. 3 Issue 1, Winter/Spring 2014

[5] Nicky Stubbs, Peterborough social impact bond seeing positive results, BLUE I\& GREEN TOMORROW, http://blueandgreentomorrow.com/2013/11/02/peterboroughsocial-impactbond-seeing-positive-results/(visited 4/20/2014)

[6] Harvard Business Review, Webinar, Sir Ronald Cohen, https://hbr.org/2013/05/the-future-of-social-impact-in.html

[7] Social Finance(UK), Web Resource http://www.socialfinance.org.uk/about-us/history

[8] Social Finance(US), \\Web Resource http://socialfinanceus.org/what-we-do/our-services

[9] Emmatomkinson.com Web Resource, https://emmatomkinson.files.wordpress.com/2014/02/uk-sibmap4.png

[10] Jeffrey Liebman \\& Alina Sellman, Social Impact Bonds: A Guide for State and Local Governments, Harvard Kennedy School Publication, 6-7 (June 2013), http://hkssiblab.files.wordpress.com/2013/07/ isocial-impact -bonds-a-guide-for-state-andlocal-governments.pdf (last visited Apr. 20, 2015) $\backslash($ discussing barriers to government budgeting for social programs)

[11] Kristina Costa et al., Frequently Asked Questions: Social Impact Bonds, $\backslash$ Ctr. For AM. Progress, $3 \backslash \backslash$ http://www.americanprogress.org/wpcontent/uploads/2012 V V 12/FAQSocialImpactBonds- 1.pdf $\backslash$ (last visited Apr. 20, 2015)

[12] Michael A. Fletcher, Can investors make money in social services?, The Washington Post, 6/10/2013, $\mathrm{http}: / / \mathrm{www}$.washingtonpost.com/business/economy/can-inve stors-make-money-in-social-services/2013/06/07/a010e7f6-c ed6-11e2-8845-d970ccb04497\_story.html

[13] Harvard Kennedy School, Social Impact Bond Technical Assistance Lab, News, http://hks-siblab.org/sibs-in-the-news/

[14] USSIF Foundation, Report on US Sustainable, Responsible and Impact Investing Trends, 2014

[15] Hanna Azemati, Michael Belinsky, Ryan Gillette, Jeffrey Liebman, Alina Sellman, and Angela Wyse, Social Impact Bonds: Lessons Learned So Far, Community Development INVESTMENT REVIEW- 23 available at http://www.frbsf.org/community-development/files/social-i mpact-bonds-lessons-learned.pdf

[16] Mulgan, Reeder, Ahlott, Bo'she, Social Impact Investment: the challenge and opportunity of Social Impact Bonds, The Young Foundation, Revised March 2010, available at http://youngfoundation.org/wp-content/uploads/2012/10/Soc ial-Impact-Investment-The-opportunity-and-challenge-of-So cial-Impact-Bonds-March-2011.pdf

[17] Begona Getierrez-Nieto, Carlos Serrano-Cinca and Juan Camon-Cala,. A credit score system for socially responsible investing. Center Emile Bernheim Research Institue in Management Sciences, CEB Working Paper No 11/028, 2011

[18] Linsey McGoey, The philanthropic state: market-state hybrids in the philanthrocapitalist turn, Volume 35, Issue 1, 2014, pages 109-125

[19] Emily Zulz, 5 Challenges for Socially Responsible Investing: BNY Mellon, Think Advisor,

http://www.thinkadvisor.com/2015/07/14/5-challenges-for-s ocially-responsible-investing-bn

[20] eroen Derwalla, Kees Koedijk, Jenke Ter Horsta,A tale of values-driven and profit-seeking social investors., Journal of Banking \& Finance, Volume 35, Issue 8, August 2011, Pages 2137-2147

[21] "Sustainable and Responsible Investing, Top 10 Frequently Asked Questions and Answers". USSIF, June 2011. http://ussif.org/resources/factsheets resources/documents/10 mediaquestions2011_final.pdf

[22] Grossman, Blake R., and William F. Sharpe. "Financial Implications of South African Divestment." Financial Analysts Journal 42, no.4 (July 1986): 15-29. doi:10.2469/faj.v42.n4.15

[23] United Nations, http://www.un.org/millenniumgoals/, last viewed $07 / 2015$

[24] "Looking Forward, Looking Back: A Hitchhiker's Guide to Research on Social and Sustainable Investment", fsinsight.org, February 1, 2013.

[25] Allen Grossman, Sarah Appleby, Caitlin Reimers, Venture Philanthropy: Its Evolution and Its Future, Harvard Business School, N9-313-111

[26] Web Resource, About Norfund, http://www.norfund.no/about-norfund/category296.html

[27] Devfin Advisers AB, Evaluation of Norwegian Business-related Assistance Uganda Case Study May 10, 2010

[28] Gaia Consulting Ltd, Evaluation of the Norwegian Investment Fund for Developing Countries (Norfund), January 2015

[29] World Bank, International Finance Corporation, IFC Performance Standards on Environmental and Social Sustainability Effective January 1, 2012 